ISSN 0103-9954

\title{
VIABILIDADE TÉCNICA DOS TANINOS DE QUATRO ESPÉCIES FLORESTAIS DE OCORRÊNCIA NO SEMI-ÁRIDO BRASILEIRO NO CURTIMENTO DE PELES
}

\section{TECHNICAL VIABILITY OF TANNINS OF FOUR FOREST SPECIES OF BRAZILIAN SEMI-ARID REGION TO SKIDDER SKINS}

\author{
Juarez Benigno Paes ${ }^{1}$ Itaragil Venâncio Marinho ${ }^{2}$ Renivaldo Araújo de Lima ${ }^{3}$ \\ Carlos Roberto de Lima ${ }^{4}$ Tatiane Kelly Barbosa de Azevedo ${ }^{5}$

\section{RESUMO}

Os taninos vegetais são encontrados em várias espécies florestais. Atualmente, os curtidores da Região Nordeste têm no angico-vermelho (Anadenanthera colubrina var. cebil), sua única fonte de taninos. Este estudo teve como objetivos avaliar o potencial tanífero e a capacidade curtente dos taninos, por meios das características físico-mecânicas das peles curtidas, de quatro espécies florestais de ocorrência no SemiÁrido brasileiro, visando a possibilitar a diversificação de espécies a serem utilizadas nos curtumes da região. Os taninos foram obtidos de angico (Anadenanthera colubrina var. cebil), cajueiro (Anacardium occidentale), jurema-preta (Mimosa tenuiflora) e de jurema-vermelha (Mimosa arenosa). Peles de caprinos foram curtidas com os taninos extraídos dessas espécies e comparadas a peles curtidas com tanino comercial de acácia negra ("Seta Natur"). Amostras de peles curtidas foram submetidas a testes de resistência à tração, ao alongamento e ao rasgamento progressivo. Verificaram-se bons resultados das peles curtidas com os taninos obtidos de jurema-preta e jurema-vermelha. Pela abundância no Semi-Árido brasileiro, a juremapreta e a jurema-vermelha apresentam potencial de exploração para obtenção de taninos, havendo a necessidade pesquisas que indiquem as melhores formas de aplicação dos taninos obtidos.

Palavras-chave: taninos vegetais; curtimento vegetal; espécies florestais do semi-árido.

\begin{abstract}
Vegetable tannins are found in several forest species. Actually, the Northeast Brazilian tanners have, on Anadenanthera colubrina var. cebil, their only source of vegetable tannins. This study aimed to evaluate the tanning capacity of tannins extracted from four vegetable species of Brazilian Semi-arid region, seeking to make possible the diversification of species to be used in tannings in the region. Thus, physical and mechanical characteristics of bovid treated skins with extract tannic of Anadenanthera colubrina var. cebil, Anacardium occidentale, Mimosa tenuiflora and Mimosa arenosa were analyzed. The bovid skins were tanned with extracted tannins of those species and compared to tanned skins by tannins of Acacia mearnsii ("Seta Natur" commercial tannin). The samples of tanned skins were submitted to tension, lengthening and progressive tear resistance tests. Good results were verified to tanned skins by Mimosa tenuiflora and Mimosa arenosa. Due to the abundance of these species in Brazilian Semi-arid region, they showed potential to exploration of tannins. However, researches are necessaries to indicate the best forms of application of obtained tannins.
\end{abstract}

Keywords: vegetable tannins; vegetable tanning; forest species from brazilian semi-arid.

INTRODUÇÃO

Os taninos são substâncias naturais, minerais ou sintéticas, capazes de precipitar as proteínas presentes nas peles para transformá-las em couro (Panshin et al.,1962; Haslam, 1966).

1. Engenheiro Florestal, Dr., Professor da Unidade Acadêmica de Engenharia Florestal, Universidade Federal de Campina Grande, CSTR, Caixa Postal, 64, CEP58700-970, Patos (PB). jbp2@uol.com.br

2. Engenheiro Florestal, ONG SOS Sertão, Rua Zuza Cabral, 18, Noé Trajano, CEP 58705-220, Patos (PB). Exbolsista PIBIC/CNPq. itaragil@ig.com.br

3. Tecnólogo Químico em Couros e Tanantes, Técnico do Centro de Tecnologia do Couro e do Calçado Albano Franco, Rua Luiz Mota, 200, CEP58108-293, Campina Grande (PB). renivaldolima@hotmail.com

4. Engenheiro Florestal, Dr., Professor da Unidade Acadêmica de Engenharia Florestal, Universidade Federal de Campina Grande, CSTR, Caixa Postal, 64, CEP58700-970, Patos (PB). crlima16@hotmail.com

5. Acadêmica do Curso de Graduação em Engenharia Florestal, Unidade Acadêmica de Engenharia Florestal, Universidade Federal de Campina Grande, CSTR, Rua José Genuíno, 719, Liberdade, CEP 58703-060, Patos (PB).

Bolsista PIBIC/CNPq tatiannebarbosa@hotmail.com

Recebido para publicação em 28/10/2005 e aceito em 16/08/2006. 
Os agentes tânicos minerais são obtidos de sais inorgânicos, à base de cromo ou zircônio. Já os taninos sintéticos são produtos derivados da condensação do fenol, cresol e naftaleno com um aldeído, como o furfural (Panshin et al., 1962). Esses produtos químicos, ou a reação deles, poderão causar danos maléficos ao homem e ao ambiente. Por isto, vários países têm dado preferência aos artigos provenientes do curtimento com taninos naturais.

Os taninos vegetais, conhecidos por taninos naturais, podem ser encontrados em várias partes do vegetal, como madeira (cerne), casca, frutos e sementes. São constituídos por polifenóis e classificados em hidrolisáveis e condensados. Os taninos hidrolisáveis são poliésteres da glicose e são classificados, dependendo do ácido formado de sua hidrólise, em taninos gálicos ou taninos elágicos (Pizzi, 1993). Já os taninos condensados são constituídos por monômeros do tipo catequina e são conhecidos por flavonóides (Haslam, 1966; Wenzl, 1970; Pizzi, 1993),

Além da importância no curtimento de peles, os taninos são utilizados pela indústria de petróleo, como agente dispersante para controlar a viscosidade de argilas na perfuração de poços (Panshin et al., 1962; Doat, 1978), sendo, também, empregados no tratamento de água de abastecimento e residuárias (Silva, 1999), na fabricação de tintas e adesivos (Trugilho et al., 1997) e, em virtude de suas propriedades antisépticas, vêm sendo testados contra organismos xilófagos (Couto, 1996; González Loredo, 1996; Shimada, 1998).

Os taninos podem representar de 2 a $40 \%$ da massa seca da casca de várias espécies florestais. Dentre as espécies tradicionalmente exploradas para a produção, destacam-se o quebracho (Schinopsis sp.) de ocorrência na Argentina e Paraguai (contém até $25 \%$ da massa seca de sua madeira de cerne em taninos) e a acácia negra (Acacia mollissima e Acacia mearnsii) de ocorrência natural na Austrália (Panshin et al., 1962; Haslam, 1966). A Acacia mearnsii é cultivada em várias regiões no Rio Grande do Sul e apresenta aproximadamente $28 \%$ de taninos na sua casca (Tanac S.A., 2005). Além dessas espécies, Haslam (1966) cita como grandes produtoras de tanino o Eucalyptus astringens (casca contendo de 40 a 50\% de taninos), o mangue-vermelho e o mangue-branco respectivamente Rhizophora candelaria e Rhizophora mangle (casca com 20 a $30 \%$ de taninos).

No Brasil há várias espécies produtoras de taninos, porém, os curtumes tradicionais da Região Nordeste que utilizam os taninos vegetais, apesar da diversidade de espécie arbóreas e arbustivas de ocorrência na região, têm no angico-vermelho (Anadenanthera colubrina (Vell.) Brenan var. cebil (Gris..) Alts.) sua única fonte de taninos (Diniz et al., 2003).

$\mathrm{O}$ consumo de cascas de angico-vermelho pelos curtumes no município de Cabaceiras, Paraíba (PB) (Latitude S7 $29^{\prime} 20^{\prime \prime}$, Longitude W36 $17^{\circ} 11^{\prime \prime}$ ) é de, aproximadamente 200 toneladas/ano. Considerando que uma árvore de angico aos 8 anos de idade (ciclo de rotação) pode produzir até $25 \mathrm{~kg}$ de cascas, seriam necessárias cerca de 8.000 árvores para suprir essa demanda. Porém, para a demanda de forma sustentada seriam necessárias, pelo menos 64.000 árvores ou, ainda, 76,8 ha de angico em povoamentos puros, considerando um espaçamento, entre plantas, de 4 × 3 metros (Marinho, 2004).

A exploração desordenada do angico, a falta de práticas adequadas de manejo ou de uma política de reflorestamento que vise à reposição das árvores exploradas e, sobretudo, a falta de outras opções de matériaprima (espécies produtoras de taninos) capazes de, em curto prazo, substituírem ou constituírem com o angico, misturas para o curtimento de couros e peles, estão colocando em risco o esgotamento dessa espécie florestal, e a falência de várias famílias que dependem dessa cadeia produtiva para o seu sustento (Diniz et al., 2003).

Este estudo teve como objetivos avaliar o potencial tanífero e a capacidade curtente dos taninos, por meios das características físico-mecânicas das peles curtidas, de quatro espécies florestais de ocorrência no Semi-Árido brasileiro, visando a possibilitar a diversificação de espécies a serem utilizadas nos curtumes da região. 


\section{MATERIAL E MÉTODOS}

\section{Espécies estudadas}

Nesta pesquisa, foi avaliado o potencial tanífero e a capacidade curtente dos taninos de quatro espécies florestais que ocorrem no Semi-Árido brasileiro, no curtimento de peles de caprinos (Tabela 1).

TABELA 1: Relação das espécies estudadas.

TABLE 1: List of studied species.

\begin{tabular}{ll}
\hline Nome Comum & \multicolumn{1}{c}{ Nome Científico } \\
\hline Angico-vermelho & Anadenanthera colubrina (Vell.) Brenan var. cebil (Gris.) Alts. \\
Cajueiro & Anacardium occidentale Linn. \\
Jurema-preta & Mimosa tenuiflora (Willd.) Poir. \\
Jurema-vermelha & Mimosa arenosa (Willd.) Poir. \\
\hline
\end{tabular}

As cascas de jurema-preta foram coletadas no Núcleo de Pesquisas do Semi-Árido (NUPEÁRIDO), município de Patos, PB, propriedade da Universidade Federal de Campina Grande (UFCG) e as de angico no Campus da UFCG em Patos, PB. As cascas de cajueiro foram extraídas no NUPEÁRIDO e no Sítio Livramento (propriedade da Sra. Maria Alves dos Santos), município de Teixeira, PB. As cascas de juremavermelha foram obtidas na Fazenda Lameirão (propriedade da UFCG), localizada no município de Santa Terezinha, PB.

Com o intuito de representar a variabilidade genética existente entre e dentre as plantas, de cada espécie amostrada, foram selecionados cinco exemplares, sendo retiradas amostras de cascas em três posições, no tronco (base, meio e topo), nos galhos e nos ramos (diâmetro de até 5,0 cm). Desse modo, a árvore foi integralmente representada.

\section{Preparo das cascas para extração dos taninos}

As cascas ao serem retiradas, foram condicionadas em sacos plásticos, para que não houvesse perda de umidade e transportadas para o Laboratório de Tecnologia de Produtos Florestais (LTPF) da Universidade Federal de Campina Grande, Centro de Saúde e Tecnologia Rural (UFCG/CSTR), Patos, PB. No laboratório, foram tomadas duas amostras de cascas de cada árvore, as quais foram cortadas em fragmentos menores, homogeneizadas, pesadas e secas em estufa a $103 \pm 2^{\circ} \mathrm{C}$ por 48 horas, para a determinação do teor de umidade (base seca) das cascas obtidas. Depois dessa operação, as cascas foram secas ao ar e moídas em uma forrageira, para obter um material de menor granulometria.

O material moído foi classificado e utilizou-se o que passou por uma peneira de malha de 2,00 x 2,00 $\mathrm{cm}$. Após essa operação, retiraram-se quatro amostras representativas de cascas de cada espécie. Duas destas foram secas a $103 \pm 2{ }^{\circ} \mathrm{C}$ por 48 horas, a fim de avaliar o teor de umidade (base seca) das cascas secas ao ar e as outras foram moídas em moinho do tipo Willey, para obtenção de um material de menor granulometria e mais homogêneo e destinadas à quantificação das substâncias tânicas presentes em cada espécie. O material restante foi utilizado nas extrações de substâncias tânicas para o curtimento de peles

\section{Extração das substâncias tânicas das cascas}

Foram executadas extrações para a quantificação das substâncias tânicas presentes em cada espécie e para a obtenção de taninos para o curtimento de peles.

\section{Extração para quantificação das substâncias tânicas}

Para a quantificação das substâncias tânicas, o material foi classificado e utilizou-se a porção que passou pela peneira de 32 "mesh" e ficou retida na de 60 "mesh". Em seguida, o material foi homogeneizado, e retiraram-se duas amostras de cada árvore, que foram pesadas e conduzidas à estufa (sob as mesmas condições já descritas) para a determinação do teor de umidade do material e para permitir os cálculos do teor de taninos presentes em cada espécie.

Para as extrações, $25 \mathrm{~g}$ de casca absolutamente seca foram colocadas em um balão de $1000 \mathrm{~mL}$ e adicionaram-se, a seguir, $500 \mathrm{~mL}$ de água destilada (relação $20: 1 ; \mathrm{v} / \mathrm{p}$ ). Ao balão foi conectado um condensador de refluxo, e o material foi mantido na temperatura de ebulição da água por duas horas, em uma manta aquecedora. 
Após a fervura, o material foi coado em uma peneira de 150 "mesh", armazenado em garrafas de plástico e conservado em geladeira, a fim de evitar o surgimento de fungos nos extratos. As cascas foram submetidas novamente ao processo de extração, com o intuito de retirar em ao máximo os taninos presentes em cada espécie. Assim a relação final casca: água foi de 1:40.

Os extratos obtidos das extrações foram transferidos para um balão volumétrico de $1.000 \mathrm{~mL}$, tendo o volume completado pela adição de água destilada. Após este procedimento, o material foi coado numa flanela e, posteriormente filtrado em cadinho de vidro sinterizado de porosidade 2 .

Do filtrado obtido, retiram-se três alíquotas de $50 \mathrm{~mL}$. Uma delas foi colocada em um copo becker de $100 \mathrm{~mL}$, e levada à estufa a $103 \pm 2^{\circ} \mathrm{C}$ durante 24 horas, para a determinação do teor de sólidos totais (TST) presente no extrato. Para as determinações do TST foi empregada a Equação 1.

$$
\operatorname{TST}(\%)=\frac{\mathrm{M}_{1}-\mathrm{M}_{2}}{\mathrm{M}_{2}} \times 100
$$

Em que: TST = Teor de sólidos totais (\%); $\mathrm{M}_{1}=$ Massa inicial (g); e $\mathrm{M}_{2}=$ Massa final (g).

As demais alíquotas foram utilizadas para a determinação do teor de taninos condensados (TTC) de cada extrato. Para tanto, foi empregado o método de Stiasny (Guangcheng et al.,1991), com algumas modificações. Assim, para a determinação do TTC, em uma amostra de $100 \mathrm{~mL}$ do extrato total foram adicionados $4 \mathrm{~mL}$ de formaldeido (37\%) e $1 \mathrm{~mL}$ de $\mathrm{HCl}$ concentrado.. Assim, para a determinação do TTC, em uma amostra de $100 \mathrm{~mL}$ do extrato total adicionaram $4 \mathrm{~mL}$ de formaldeido $(37 \%)$ e $1 \mathrm{~mL}$ de $\mathrm{HCl}$ concentrado. O material foi aquecido, sob refluxo durante 30 minutos. Nessa condição, os taninos formaram complexos insolúveis, que foram separados por filtragem simples ao empregar filtro de papel.

Após a filtragem, o material foi transferido para um copo Becker de $250 \mathrm{~mL}$ e seco a $103 \pm 2{ }^{\circ} \mathrm{C}$, por 24 horas. Após a secagem, calculou-se o Índice de Stiasny, conforme Equação 2.

$$
I(\%)=\left(\frac{M_{2}}{M_{1}}\right) \times 100
$$

Em que: $\mathrm{I}=$ Índice de Stiasny (\%); $\mathrm{M}_{1}=$ Massa de sólidos em $100 \mathrm{~mL}$ de extrato; $\mathrm{M}_{2}=$ Massa do precipitado taninos - formaldeido.

Após a obtenção do Índice de Stiasny foi calculado o teor de taninos condensados (TTC), conforme a Equação 3.

$$
\text { TTC } \%=\frac{\text { TST } \times 1}{100}
$$

Em que: TTC = Teor de taninos condensados (\%); TST = Teor de sólidos totais (Equação 1); I = Índice de Stiasny (Equação 2).

Todas as análises foram realizadas em duplicatas. Assim, foram realizadas dez valiações para cada espécie, totalizando quarenta análises.

\section{Extrações das substâncias tânicas para o curtimento de peles}

A extração dos taninos a serem utilizados no curtimento de peles foi em água, à temperatura de $70 \pm$ $5^{\circ} \mathrm{C}$, durante duas horas. Nas extrações, para cada $2,00 \mathrm{~kg}$ de cascas foram adicionados 10 litros de água (relação 5:1). Cada amostra foi submetida à fervura, em um digestor rotativo, com capacidade de 20 litros. Essa operação foi executada no LTPF (UFCG/CSTR). Cada amostra de casca foi submetida a duas extrações. Assim, a relação final foi de 1:10.

Após cada extração, o material foi passado em uma peneira com tecido de "silk screen" e em um tecido de flanela, para a retenção de partículas finas.

O extrato obtido foi homogeneizado e derramado em bandejas de alumínio de 5 x 40 x $60 \mathrm{~cm}$, e posto em uma estufa de ventilação forçada mantida a $70 \pm 3^{\circ} \mathrm{C}$, até a completa evaporação da umidade. $\mathrm{O}$ material seco obtido foi moído em um multiprocessador de uso doméstico e peneirado em peneira de 60 mesh. Essas etapas foram repetidas até a obtenção de, no mínimo, 500 gramas de taninos para cada espécie 
florestal, quantidade essa, tida como a mínima necessária para o curtimento de peles, que foram submetidas aos testes físico-mecânicos, no Centro de Tecnologia do Couro e do Calçado "Albano Franco" (CTCC) SENAI, Campina Grande, PB.

\section{Curtimento e testes físico-mecânicos das peles curtidas}

$\mathrm{O}$ curtimento das peles de caprinos e os testes físico-mecânicos necessários à avaliação do curtimento com os taninos foram realizados no CTCC. As peles de caprinos, utilizadas no experimento, foram obtidas de animais de mesma faixa etária, provenientes da Cooperativa dos Curtidores e Artesãos em Couro de Ribeira de Cabaceiras Ltda. (ARTEZA), situada em Cabaceiras, PB.

Para o curtimento das peles, seguiram-se os procedimentos, normalmente utilizados pelo CTCC, para o curtimento com taninos industriais de acácia negra (Acacia mearnsii), a qual foi utilizada nos testes como controle para as peles curtidas com os taninos das espécies testadas. Para os testes físico-mecânicos, foram utilizadas três peles por tratamento, as quais passaram pelos processos de pré-curtimento, curtimento, recurtimento, secagem e amaciamento. Dessas operações, apenas o curtimento foi executado individualmente para cada tanino testado.

Após o processo de curtimento que envolveu as etapas já citadas, foram realizados testes de resistência à tração e ao alongamento (Associação Brasileira de Normas Técnicas - ABNT - NBR 11041, 1997) e de resistência ao rasgamento progressivo (ABNT - NBR 11055, 1997).

\section{Avaliação e análise dos resultados}

Para a avaliação e análise dos resultados de TTC obtidos para cada espécie foi empregado um delineamento inteiramente casualisado e as médias comparadas pelo teste de Tukey $(p \geq 0,05)$. Os valores de TTC foram transformados em arcsen [raiz (TTC/100)]. Essa transformação dos dados sugerida por Steel e Torrie (1980) foi necessária para homogeneizar as variâncias.

Para a avaliação e análise dos resultados do curtimento (testes físico mecânicos nas peles curtidas), foi empregado um delineamento inteiramente casualisado, com arranjo fatorial, em que se avaliaram os efeitos dos taninos, da direção dos testes nas peles e a interação desses efeitos. O potencial curtente dos taninos das espécies florestais do Semi-Árido brasileiro foi comparado ao do produto comercial "Seta Natur," obtido de acácia negra (Acacia mearnsii), produzido pela Seta S.A., que é largamente empregado no curtimento de peles. Para a análise e avaliação dos ensaios, foi empregado o teste de Tukey $(p \geq 0,05)$.

\section{RESULTADOS E DISCUSSÂO}

Na Tabela 2, são apresentados os valores médios da espessura e do teor de umidade das cascas de cada espécie. Observa-se, nessa tabela, que o cajueiro e a jurema-preta apresentaram as cascas mais espessas, quando comparadas às demais. Isso indica um maior rendimento de casca por árvore.

A variação observada entre a umidade das cascas deve-se, possivelmente, ao período de sua coleta. $\mathrm{O}$ angico e o cajueiro foram coletados durante o período de estiagem, enquanto a jurema-preta e a juremavermelha foram coletadas no período chuvoso.

TABELA 2: Valores médios da espessura e do teor de umidade das cascas de cada espécie.

TABLE 2: Averages values of thickness and moisture content of bark of all species.

\begin{tabular}{lcc}
\hline Espécies estudadas & Espessura media das cascas (mm) & Teor de umidade das cascas (\%) \\
\hline Angico-vermelho & 6,49 & 54,37 \\
Cajueiro & 8,36 & 59,40 \\
Jurema-preta & 6,41 & 75,62 \\
Jurema-vermelha & 4,62 & 82,65 \\
\hline
\end{tabular}

A média do teor de umidade das cascas seca ao ar, TST (\%); Índice de Stiasny, médias do teor de taninos condensados e a quantidade de taninos por espécie, por tonelada de casca seca, encontram-se na Tabela 3. 
TABELA 3: Valores médios da umidade da casca seca ao ar, do TST, índice de Stiasny, TTC e dos taninos por tonelada de casca seca.

TABLE 3: Average values of moisture content of air dried bark of the TSC, Stiasny's index of CTC and tannins by ton of dry bark.

\begin{tabular}{l|c|c|c|c|c}
\hline Espécies estudadas & TU (\%) & TST (\%) & IS (\%) & TTC (\%) & TTCS (kg) \\
\hline Angico-vermelho & 7,93 & 22,48 & 52,88 & $11,89 \mathrm{~b}$ & 118,90 \\
Cajueiro & 9,72 & 33,36 & 59,45 & $19,83 \mathrm{a}$ & 198,30 \\
Jurema-preta & 8,96 & 26,32 & 67,39 & $17,74 \mathrm{a}$ & 177,40 \\
Jurema-vermelha & 9,57 & 24,64 & 73,48 & $18,11 \mathrm{a}$ & 181,10 \\
\hline
\end{tabular}

Em que: TU $=$ teor de umidade; TST $=$ teor de sólidos totais; IS = índice de Stiasny; TTC $=$ teor de taninos condensados; TTCS $=$ taninos por toneladas casca seca. As médias seguidas pela mesma letra não diferem estatisticamente pelo teste de Tukey ( $\mathrm{p} \geq 0,05)$.

O teor de umidade das cascas seca ao ar variou de 7,93 (angico) a 9,72 (cajueiro), o que facilitou a moagem, tendo-se pouca perda na forma de finos e pouca incrustações nas facas do moinho.

Dentre as espécies estudadas, o angico e a jurema-preta apresentaram os maiores valores de TST, e os maiores Índices de Stiasny foram obtidos para jurema-preta e jurema-vermelha.

O Índice de Stiasny encontrado para o angico foi próximo ao obtido por Trugilho et al. (1997) para árvores que crescem na região de Cerrado, próximo a Lavras, MG, porém, os autores encontraram um teor de taninos de $18,51 \%$. A diferença encontrada pode estar relacionada à idade das árvores estudadas, à posição nas árvores em que foram coletadas as cascas que, no caso, foram provenientes apenas de galhos, e à qualidade do sítio.

A maior quantidade de taninos condensados (Tabela 3) foi observada para o cajueiro, jurema-preta e jurema-vermelha. Essas espécies apresentaram teores de taninos superiores ao angico-vermelho, espécie tradicionalmente explorada na Região Nordeste do Brasil pela indústria de curtumes.

Observa-se, na Tabela 3, que as espécies que apresentaram um maior TST, também apresentaram um maior TTC. Exceção feita à jurema-vermelha que teve o TST menor que a jurema-preta, tendo apresentado um maior TTC. Isso pode ter ocorrido em função da maior pureza do extrato da jurema-vermelha.

Uma estimativa da quantidade em kg de tanino condensado por tonelada de casca seca (Tabela 3) revela o potencial do cajueiro, jurema-preta e jurema-vermelha como produtoras de taninos.

Observa-se que o cajueiro (Tabela 3) possui casca mais espessa que as demais espécies, o que indica um maior rendimento de casca por árvore.

Os valores médios, provenientes dos testes físico-mecânicos, para as amostras de peles curtidas, encontram-se na Tabela 4, com a respectiva análise estatística, e nas Figuras 1, 2 e 3, em que são comparados às exigências técnicas mínimas para cada teste.

Com base nos dados apresentados na Tabela 4 e Figura 1, pode-se afirmar que as peles curtidas com os taninos extraídos de jurema-preta apresentaram o melhor resultado para o teste de resistência à tração, na direção paralela às fibras. $\mathrm{Na}$ direção perpendicular às fibras, os melhores resultados foram obtidos pelas peles curtidas com os taninos de jurema-vermelha, jurema-preta e angico-vermelho. Esses resultados foram superiores, estatisticamente, aos da pele curtida com acácia-negra. Na direção perpendicular às fibras, apenas a pele curtida com os taninos de jurema-vermelha atingiu resultado superior ao da exigência técnica mínima para couros, que é de $18 \mathrm{~N} / \mathrm{mm}^{2}$, e na direção paralela às fibras, todos os taninos testados superaram a exigência técnica mínima. 
TABELA 4: Resultados dos ensaios mecânicos em peles de caprinos curtidas com os taninos obtidos.

TABLE 4: Results of mechanical assays in skins of bovid tanned with obtained tannins.

\begin{tabular}{l|cc|c|c|c|c}
\hline \multirow{2}{*}{$\begin{array}{c}\text { Espécies } \\
\text { (Taninos) }\end{array}$} & \multicolumn{2}{|c|}{ Tração $\left(\mathrm{N} / \mathrm{mm}^{2}\right)$} & \multicolumn{2}{c|}{ Alongamento (\%) } & \multicolumn{2}{c}{ Rasgamento $\left(\mathrm{N} / \mathrm{mm}^{2}\right)$} \\
\cline { 2 - 7 } & Paralela & Perpendicular & Paralela & Perpendicular & Paralela & Perpendicular \\
\hline Acácia-negra & $22,41 \mathrm{Ba}$ & $13,61 \mathrm{Bb}$ & $41,50 \mathrm{Bb}$ & $56,51 \mathrm{Aa}$ & $40,43 \mathrm{Aa}$ & $42,35 \mathrm{Aa}$ \\
Angico-vermelho & $19,64 \mathrm{Bca}$ & $17,48 \mathrm{Aa}$ & $50,94 \mathrm{Aa}$ & $48,84 \mathrm{Ba}$ & $42,07 \mathrm{Aa}$ & $42,70 \mathrm{Aa}$ \\
Cajueiro & $18,46 \mathrm{Ca}$ & $15,30 \mathrm{Bb}$ & $50,71 \mathrm{Aa}$ & $44,67 \mathrm{Bb}$ & $40,86 \mathrm{Aa}$ & $41,32 \mathrm{Aa}$ \\
Jurema-preta & $26,53 \mathrm{Aa}$ & $17,70 \mathrm{Ab}$ & $31,50 \mathrm{Cb}$ & $50,76 \mathrm{ABa}$ & $32,35 \mathrm{Bb}$ & $38,62 \mathrm{Aa}$ \\
Jurema-vermelha & $20,34 \mathrm{Bca}$ & $18,09 \mathrm{Aa}$ & $42,72 \mathrm{Bb}$ & $49,78 \mathrm{ABa}$ & $40,64 \mathrm{Aa}$ & $38,27 \mathrm{Aa}$ \\
\hline
\end{tabular}

Em que: As médias seguidas pela mesma letra, maiúscula na vertical, ou minúscula na horizontal, não diferem estatisticamente pelo teste de Tukey ( $\mathrm{p} \geq 0,05)$.

Para o teste de alongamento, na direção paralela às fibras, as peles curtidas com taninos de cajueiro e de angico-vermelho apresentaram os melhores resultados e, na direção perpendicular às fibras, estes presentaram os piores resultados. Apenas a pele curtida com jurema-preta ficou abaixo de $40 \%$, exigência técnica mínima para o teste (Figura 2).

$\mathrm{Na}$ análise dos dados do teste de rasgamento progressivo (Tabela 4 e Figura 3), excluindo-se a pele curtida com jurema-preta e aplicação da carga na direção paralela às fibras, todos os resultados foram semelhantes estatisticamente, e as peles curtidas com taninos das espécies testadas são indicadas para confecção de calçados com forro (exigência técnica mínima de $34,3 \mathrm{~N} / \mathrm{mm}^{2}$ ).

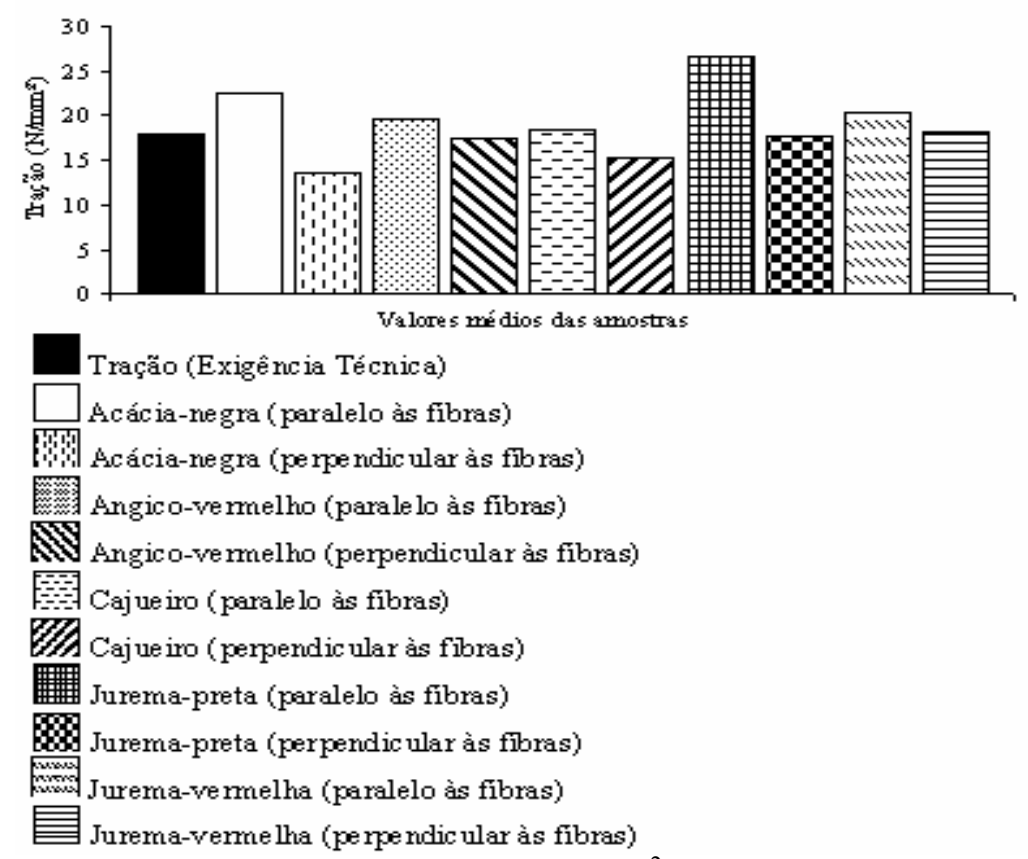

FIGURA 1: Comparação entre a resistência à tração $\left(\mathrm{N} / \mathrm{mm}^{2}\right)$ para as peles curtidas com os taninos das espécies estudadas e as exigências técnicas mínimas para o teste.

FIGURE 1: Comparison among the resistance to tension $(\mathrm{N} / \mathrm{mm} 2)$ for tanned skins to studied species and the minimum techniques demanded for test. 


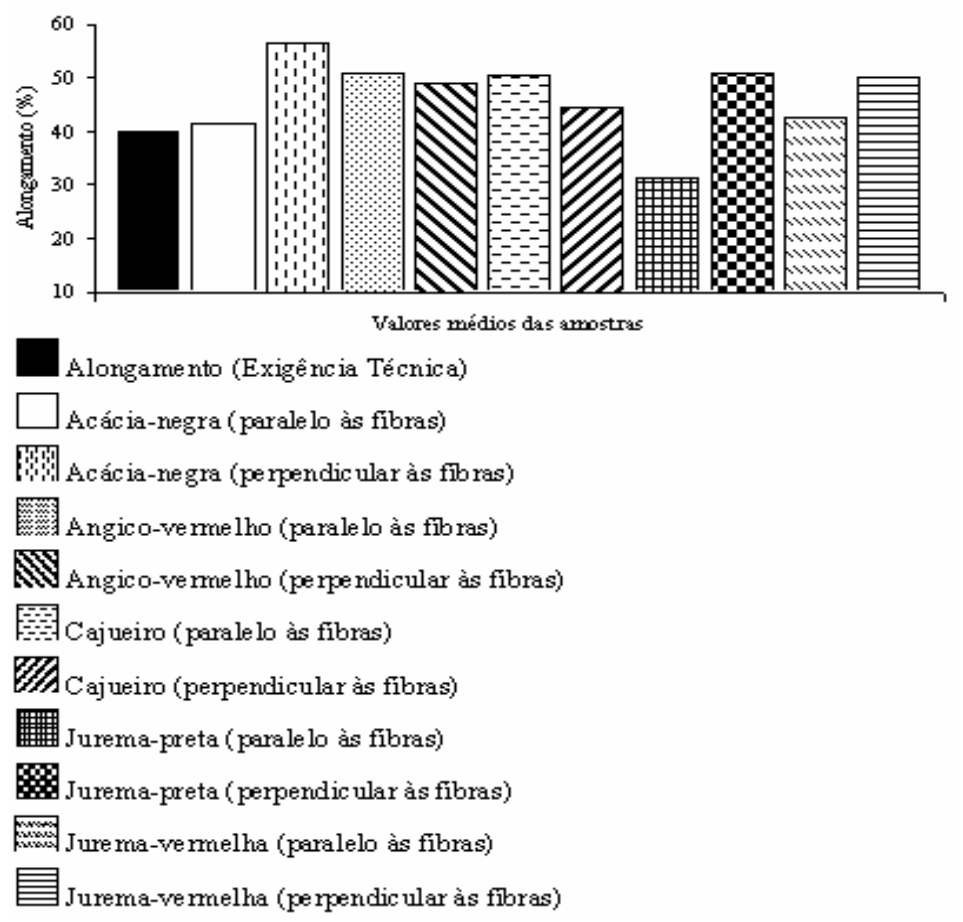

FIGURA 2: Comparação entre a resistência ao alongamento (\%) para as peles curtidas com os taninos das espécies estudadas e as exigências técnicas mínimas para o teste.

FIGURE 2: Comparison among the resistance to lengthening (\%) for tanned skins to studied species and the minimum techniques demanded for test.

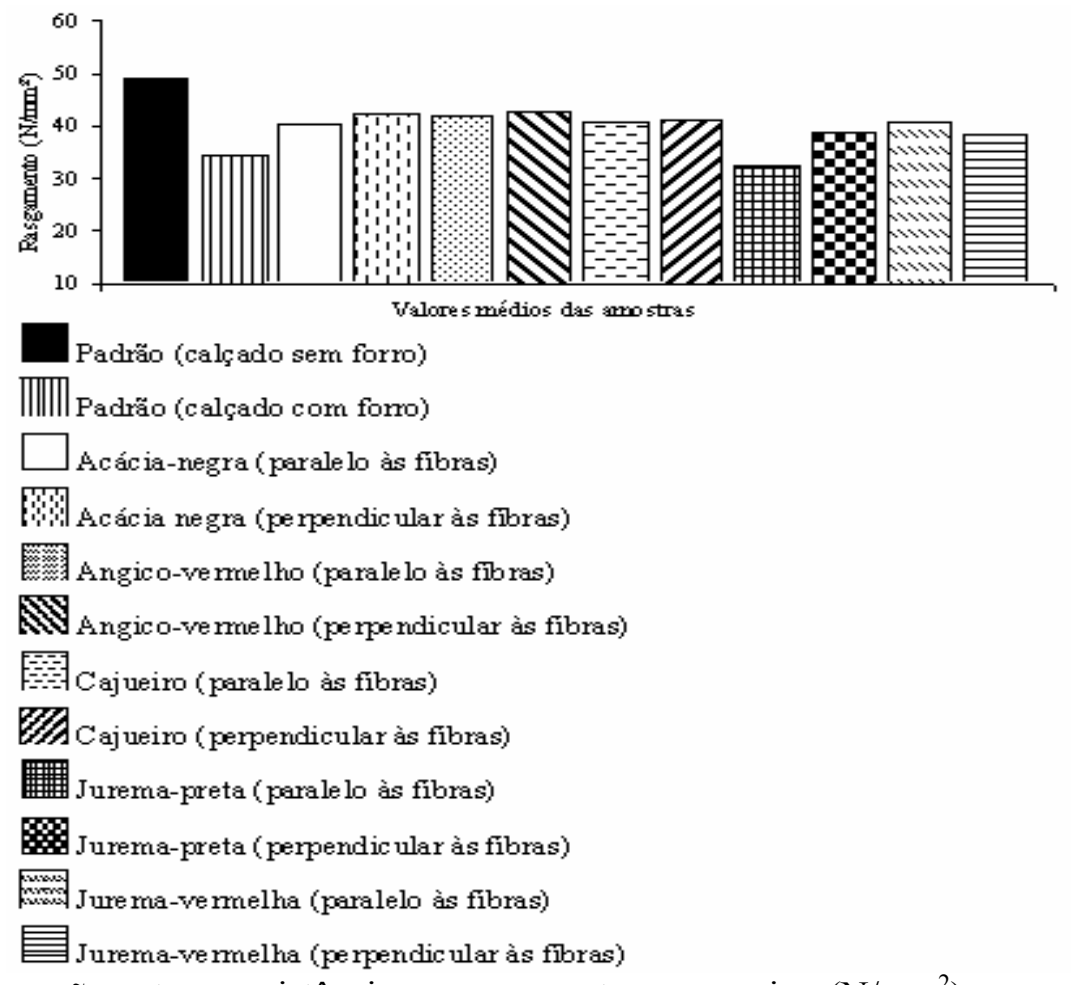

FIGURA 3: Comparação entre a resistência ao rasgamento progressivo $\left(\mathrm{N} / \mathrm{mm}^{2}\right)$ para as peles curtidas com os taninos das espécies estudadas e as exigências técnicas mínimas para o teste.

FIGURE 3: Comparison among the resistance to progressive tear resistance $(\mathrm{N} / \mathrm{mm} 2)$ for tanned skins to studied species and the minimum techniques demanded for test. 
Esses resultados indicam o potencial dos taninos extraídos das espécies florestais de ocorrência no Semi-Árido brasileiro, para o curtimento de peles, porém há a necessidade de pesquisas que indiquem as melhores formas de aplicação desses taninos para a indústria de curtume e de outros usos, em que os taninos vegetais são empregados.

\section{CONCLUSÕES}

A jurema-preta, em função da quantidade de taninos apresentada em sua casca e sobretudo por ser uma espécie de alta densidade florística no Semi-Árido brasileiro, apresenta potencial para ser utilizada como produtora de taninos. No entanto, são necessárias pesquisas para avaliar a qualidade dos taninos para o curtimento e recurtimento de peles e também para outros usos.

O extrato tânico da jurema vermelha teve um índice de Stiasny superior aos das demais espécies estudadas e, a exemplo da jurema-preta, necessita de mais estudos para verificar a viabilidade técnica e econômica de seu emprego em curtumes e em outros usos.

Os taninos obtidos de cajueiro, jurema-preta e jurema-vermelha apresentaram capacidade curtente para peles de caprinos, representada pelos valores de resistência das peles curtidas, o que contribui para $o$ alivio da pressão exercida sobre populações remanescentes de angico-vermelho.

\section{AGRADECIMENTOS}

Os autores agradecem ao Centro de Tecnologia do Couro e do Calçado "Albano Franco" e à Coordenação do Programa COMPET/SICTCT do Estado da Paraíba, pelo apoio técnico, ao SEBRAE e ao CNPq (Programa de Bolsa de Iniciação Científica), pelo apoio financeiro concedido à pesquisa.

\section{REFERÊNCIAS BIBLIOGRÁFICAS}

ASSOCIAÇÃO BRASILEIRA DE NORMAS TÉCNICAS. NBR 11041 : couro : determinação da resistência à tração e alongamento. Rio de Janeiro: ABNT, 1997. 5p.

ASSOCIAÇÃO BRASILEIRA DE NORMAS TÉCNICAS. NBR 11055 : couro : determinação da força de rasgamento progressivo. Rio de Janeiro: ABNT, 1997. 4p.

COUTO, L.C. Potentiel fongicide dês extraits d'écorce de barbatimão à l'état brut et combines aux íons $\mathrm{Fe}^{+++}$et $\mathbf{A l}^{+++}$. 1996. 262f. Thèse (Philosophiae Doctor) - Faculté de Foresterie et de Géomatique, Université Laval, Québec, 1996.

DINIZ, C.E.F.; PAES, J.B.; MARINHO, I.V.; et al. Avaliação do potencial tanífero de seis espécies florestais de ocorrência no semi-árido brasileiro. In: CONGRESSO FLORESTAL BRASILEIRO, 8., 2003, São Paulo. Anais... São Paulo: SBS/SBEF, 2003. 1 CD-ROM.

DOAT, J. Les tanins dans les bois tropicaux. Bois et forêsts des tropiques, Nogent-sur-Marne, v. 182, p.35-7, 1978.

GONZÁLEZ LOREDO, R.F. Preservación de madera con taninos. Madera y Bosques, México, v.2, n.2, p. 67-73, 1996.

GUANGCHENG, Z.; YUNLU, L.; YAZAKI, Y. Extractive yields, Stiasny values and polyflavonoid contents in barks form six acacia species in Australia. Australian Forestry, Queen Victoria, v. 554, n. 2, p.154-156, 1991.

HASLAM, E. Chemisty of vegetable tannins. London: Academic Press, 1966. 170p.

MARINHO, I.V. Avaliação do potencial tanífero das cascas do angico vermelho Anadenanthera colubrina (Vell.) Brenan var. colubrina (Vell.) Brenan e do cajueiro Anacardium occidentale Linn. em diferentes reagentes. 2004. 36f. Monografia (Graduação em Engenharia Florestal) - Universidade Federal de Campina Grande, Patos, 2004.

PANSHIN, A.J.; HARRAR, E.S.; BETHEL, J. S.; BAKER, W. J. Forest products: their sources, production, and utilization. 2.ed. New York: McGraw-Hill, 1962. 538p.

PIZZI, A. Tannin-based adhesives. In: Pizzi, A. (Ed.). Wood adhesives: chemistry and technology. New York: Marcell Dekker, 1993. p.77-246.

SHIMADA, A.N. Avaliação dos taninos da casca de Eucalyptus grandis como preservativo de madeira. 1998. $56 f$. Dissertação (Mestrado em Ciência Florestal) - Universidade Federal de Viçosa, Viçosa, 1998.

SILVA, T.S.S. Estudo de tratabilidade físico-quinica com uso de taninos vegetais em água de abastecimento e de esgoto. 1999. 87f. Dissertação (Mestrado em Saúde Publica) - Fundação Oswaldo Cruz, Escola Nacional de Saúde Publica, Rio de Janeiro, 1999. 
STEEL, R.G.D.; TORRIE, J.H. Principles and procedures of statistic: a biometrical approach. 2.ed. New York: Mc Graw Hill, 1980. 633p.

TANAC S.A. Construindo o futuro todos os dias. Disponível em:

$<$ http://www.tanac.com.br/PT/institucional.php?codCategoriaMenu=148\&nomArea=Hist\%C3\%B3rico\&codDado=2\& menu=138>. Acesso em: 21 dez. 2005.

TRUGILHO, P.F., et al. Avaliação do conteúdo em taninos condensados de algumas espécies típicas do cerrado mineiro. Cerne, Lavras, v.3, n.1, p.1-13, 1997.

WENZL, H.F.J. The chemical technology of wood. New York: The Academic Press, 1970. 692p. 